\title{
Strategies of Reading Promotion in the Construction of Library Alliance of Small and Medium Cities in Mobile Internet Era
}

\author{
Chai Rong \\ Xi'an Aeronautical Polytechnic Institute, Library, Xi'an, Shaanxi, 710089
}

Keywords: library reading; mobile Internet; promotion strategy

\begin{abstract}
With the development of the Internet, mobile Internet technology has been applied to various fields. Traditional reading methods can no longer meet the needs of modern people for reading and acquiring knowledge. The reading of small and medium-sized urban libraries must inevitably adapt to the development of the times, and advancing with the times is indispensable. It is necessary to fully realize that the use of mobile internet thinking is an opportunity to promote the rapid development of traditional library systematic reading. However, mobile reading also has many restrictive factors such as complex service market, drawbacks of the mobile Internet itself, and the need to improve the quality of librarians. Therefore, it is necessary to adopt appropriate strategies to overcome these drawbacks. Knowledge and information sharing can be valued in a form-based, content-centric way. The three-dimensional promotion strategy can be used to enhance the necessary differentiated competitiveness. Effective strategies are transmitted in a timely manner. The new reading mode of the library under the thinking of mobile Internet is established to promote library reading.
\end{abstract}

\section{Introduction}

With the rapid development of mobile Internet, mobile reading has entered a golden era of development. Fragmented reading makes "light reading" and "pan-reading" fill people's lives. Therefore, mobile internet is both an opportunity and a challenge for reading. The vigorous development of the mobile Internet has prompted small and medium-sized city libraries to think about how to use new technologies to plan their own development and meet the needs of modern readers. The new strategy was adopted to suit readers' reading style in the mobile Internet era. Therefore, how small and medium-sized urban libraries read through the methods of adapting to the development of the times to promote readers to read and meet readers' diversified reading needs has become an important part of library reading promotion.

\section{Opportunities and Challenges of Mobile Internet Thinking to Promote Library Reading}

Library reading is bound to adapt to the development of the times and advancing with the times is essential. However, the shallow reading-based form of "superficial reading" and "pan-reading" cannot replace the traditional means of deep reading and systematic knowledge acquisition. The use of modern information science and technology, the perfect integration of various high-tech reading methods, and the use of mobile Internet thinking are opportunities for the rapid development of systematic reading in traditional libraries.

Light reading phenomenon. With the development of economic times and the acceleration of the pace of life, mobile reading has brought us convenience and entertainment while shallow reading has become more and more serious. Many people are bored with lengthy text and do not have enough patience to read. Some people read shallowly and think that they understand the central idea of the article. In fact, it is only taken out of context. This poor means of transmitting knowledge and bad reading habits can easily make the mind lazy and make the thinking and judgment gradually decline. It will make people more dependent and lose their interest in deep understanding of knowledge. Second, it has a bad influence on readers' values and outlook on life. Furthermore, it is not conducive to inheriting civilization and disseminating knowledge. The harm to young readers 
needs to be taken seriously.

The quality of librarians needs to be improved. Librarians need to help readers find useful information in a vast array of books. It is an important part of promoting library reading under the thinking of mobile internet. However, the quality and ability of librarians in small and medium-sized cities are still very weak, which has become an obstacle to the promotion strategy of mobile reading libraries. Librarians in the new situation not only need to be familiar with the Internet, but also have professional qualities and comprehensive knowledge. While handling the navigation of readers, they can constantly enrich themselves, accept new technologies and new methods, adapt to the development of new libraries, and advance with the times.

\section{Strategy of Mobile Internet Thinking to Promote Library Reading}

The thinking of the mobile internet has spread to everyone, emphasizing personalized services and paying attention to user experience. The vigorous development of mobile reading has prompted small and medium-sized urban libraries to think about how to use the emerging new technologies to formulate new strategies that are more in line with their own development needs in order to meet the needs of citizens' reading in the era of mobile Internet. How the library meets the needs of its readers is an urgent issue that needs to be addressed.

By focusing on the quality of reading content and advocating deep reading and diversified reading methods, it can achieve the purpose of opening up readers' thinking space, cultivating readers' critical spirit, and stimulating readers' unlimited imagination. Therefore, the information and knowledge of library promotion must be carefully selected and the content is accurate and rich. There are not only good books but also media articles, celebrity introductions, lectures, book fair notices, and classic guides readers to promote reading related information.

In view of the shortcomings of the Internet itself, the content that libraries push to readers should eliminate pornography, which is not conducive to physical and mental development. In addition, librarians and other information workers should respect personal privacy and protect personal data in the process of sharing information, and librarians must not harm readers' interests. Therefore, librarians should actively participate in information disclosure, expose and stop abnormal readers' behavior. Librarians should crack down on illegal and criminal ACTS and protect the privacy of readers.

The library reading under the thinking of mobile internet can learn the OTO experience of news reading end. It can create good conditions to convert online behaviors such as login, reading, speaking, commenting, and sharing into grades, and readers can then go to the library in exchange for corresponding reading resources or rewards. This will not only increase the enthusiasm of online participation, but also develop and make use of the library's resources. First, with the help of the wireless diffusion function of the mobile Internet, the activities of book fairs and book clubs under the line are vigorously promoted, so that more people can participate in it. Second, online reading and sharing can be translated into offline real benefits, which can effectively promote online participation enthusiasm and make the services of the mobile Internet library extend to the entire society.

Mobile Internet technology provides readers with convenient, practical and practical services. But on this basis, the real-time nature of information and knowledge needs to be guaranteed. The answers to new questions, new knowledge issues and doubtful questions and reading guidance are delivered to the reader in a timely and effective manner. It can reduce the blindness of readers, save readers time, and increase readers' enthusiasm for reading. Librarians can also statistically analyze readership and divide readers into different fields or different levels of information needs, and they provide more targeted personalized reading pushes for readers at all levels. This will not only save resources but also eliminate readers' troubles in finding useful resources, increase readers' interest, and deliver new news and resources to readers in real time. 


\section{Conclusion}

The library is a growing organism. In the era of rapid development of mobile Internet, both university libraries and social libraries must adapt to the development of society and the needs of readers. Small and medium-sized city libraries should actively face difficulties and challenges. They must absorb the advantages of socialized reading and consciously take responsibility. Libraries should give full play to their rich, systematic resources and intellectual advantages, and effectively promote citizens' reading in the era of mobile Internet. Mobile Internet thinking has achieved the goal of spreading to everyone, focusing on user experience and being more human. On the premise of ensuring systematic and profound traditional reading, it has launched mobile reading promotion service. It analyzes the different needs and changes of different readers and transmits the latest resources and information in time. By using new media technologies to enrich the reading styles of small and medium-sized cities, the library can give full play to its guiding role in people's reading and acquiring knowledge.

\section{References}

[1] Wang Xiaofang. Library service innovation strategy under micro-era background [J]. Library Journal 2014(5): 79 - 81.

[2] Ma Jiangbao. Study on the reading promotion strategy of college libraries in the mobile micro-era [J]. Henan Library Journal, 2015(2): 46 - 48.

[4] Yang Jie, Yuan Yongcui. American Public Library MOOC Service Practice and Enlightenment [J]. Library Construction, 2015(2): 97 - 100.

[5] Shen Xiuqiong. Study on University Library Resource Construction Strategy for MOOC [J]. Library and Information Service, 2014(11): 33 - 37.

[6] Wang Hong, Ma Dongming. Localization Development and Its Influence on University Libraries [J]. University Library Work, 2014(6): 44 - 47. 